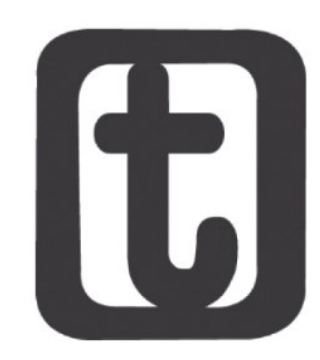

\title{
SOBRE A LEI MARIA DA PENHA E AS MEDIDAS DE PROTEÇÃO DE URGÊNCIA JUDICIAIS
}

\author{
Reflections over the Lei Maria da Penha and judicial urgency protection measures
}

\author{
Emilly Marques Tenorio*
}

\begin{abstract}
RESUMO
O artigo traz reflexões sobre a proteção social ofertada às mulheres que requisitaram medidas de proteção de urgência judiciais previstas na "Lei Maria da Penha" (Lei 11.340/2006). Resulta de pesquisa documental que analisou tais ações em uma vara especializada em violência doméstica e familiar contra a mulher, com a intenção de identificar o direcionamento dado às medidas. A partir do universo estudado reflete sobre os limites da proteção social na implementação dessa legislação a partir de alguns elementos centrais: a) dificuldade deacesso à justiça; b) reprodução do machismo institucional; c) punitivismo estatal ed) falta de transversalidade das ações. Como resultados, percebemos que a "proteção social" ofertada à mulher são as mais superficiais e imediatistas, que não demandam maiores investimentos em políticas públicas. Voltam-se para a restrição de direitos dos homens (principais denunciados), em detrimento de políticas públicas direcionadas à prevenção das violências ou acompanhamento para os/as envolvidos/as, trazendo um reducionismo ao próprio espírito da lei e conservando o tradicional papel do Direito.
\end{abstract}

\section{PALAVRAS-CHAVE}

Lei Maria da Penha. Medidas de proteção de urgência. Violência doméstica e familiar contra as mulheres. Proteção social.

\begin{abstract}
The article dialogues over social protection offered to women that demanded judicial urgency protection measures forecasted on "Lei Maria da Penha" (Law 11.340/2006). It results from the of documentaryresearch which analyzed such actions in a specialized court for domestic violence against women, with the intention of identifying the direction given to the orders. From the studied universe it ponders about the limits of social protection on implementing this law mediated by some elemental aspects: a) difficulty accessing justice; b) propagate institutional sexism; c) state-hold punitivism; d) lack of transversality of actions.As per the results, we've noticed that "social protection" offered to women are the most superficial, characterized by immediacy, disregarded of public investment. Those measures aim towards men's right restriction (for they are the most denounced), and deny violence prevention or attendance for those who are implicated in the process, reducing the own spirit of the law, as well as reserving the traditional role of the law.
\end{abstract}

\section{KEYWORDS}

Lei Maria da Penha. Urgency protection measures. Domestic violence against women. Social protection.

\footnotetext{
* Assistente Social. Mestra em Política Social. Assistente Social do Tribunal de Justiça do Estado do Espírito Santo. (TJES, Vitória, Brasil). Rua Desembargador Homero Mafra, 60, Enseada do Suá, Vitória (ES), CEP.: 29050-906. Conselheira do Conselho Regional de Serviço Social do Espírito Santo (CRESS $17^{a}$ Região) - Gestão "Tempos de Resistir" (2017-2020). ORC ID: <http://orcid.org/0000-0002-3922-0495>. E-mail: <emillypmarques@gmail.com>.
} 


\title{
INTRODUÇÃO
}

\begin{abstract}
"[...] a proibição de sair, a proibição de se dizer o que se pensa, a proibição de fazer o que se sente, e a humilhação pública são alguns dos métodos de penitência e tortura tradicionais na vida da família. Para castigo à desobediência e exemplo de liberdade, a tradição familiar perpetua uma cultura do terror que humilha a mulher, ensina os filhos a mentir e contagia tudo com a peste do medo. - Os direitos humanos deveriam começar em casa - comenta comigo, no Chile, Andrés Domínguez" (Eduardo Galeano, A cultura do terror/4).
\end{abstract}

O artigo apresentado traz elementos advindos da pesquisa ${ }^{1}$ de dissertação de mestrado em Política Social, na qual debatemos a proteção social - não ou pouco - obtida nas requisições judiciais de medidas de proteção tipificadas na Lei 11.340/2006, a Lei Maria da Penha (LMP), em uma perspectiva crítico-feminista (TENORIO, 2017). Tal legislação é considerada pela Organização das Nações Unidas (ONU), desde 2012, uma das três melhores legislações no enfrentamento à violência contra a mulher em âmbito mundial, atrás apenas da Espanha e Chile ${ }^{2}$. Porém, segundo dados do último Atlas da Violência (2017), no ano de 2015, 4.621 mulheres foram assassinadas e houve um crescimento de $22 \%$ da mortalidade de mulheres negras no período de 10 anos (2010-2015).

O objetivo desse artigo é refletir, em uma análise materialista histórico-dialética, sobre a proteção social ofertada às mulheres que acionam o Estado pelo viés da judicialização ao requisitarem medidas de proteção de urgência (MPUs) tipificadas na Lei Maria da Penha. Conforme destacado por Clara Zetkin, "[...] a visão materialista da história não nos deu, é verdade, respostas prontas à questão das mulheres, mas nos deu algo melhor. O método correto e preciso de estudo e compreensão da questão" (ZETKIN apud ANDRADE, 2011, p. $6)$.

Para tanto, necessariamente devemos analisar as condições concretas de vida das mulheres, em sua diversidade, no tempo histórico atual e os limites da proteção social nesse sistema que consideramos estruturalmente desigual. O acionamento da LMP constitui-se como uma das diversas tentativas de romper com a violência doméstica e familiar. Tal expressão da violência, não é a única vivenciada por nós, porém constitui-se uma forma específica de desumanização das mulheres, que ganhou visibilidade prioritariamente, ao nosso ver, com: 1) a luta do movimento feminista com campanhas, ações diretas e atos políticos ${ }^{3}$ ) a construção e aprovação da Lei Maria da Penha que foi

\footnotetext{
${ }^{1} \mathrm{O}$ pesquisa foi submetida e aprovada pelo Comitê de Ética em Pesquisa da Universidade Federal do Espírito Santo (UFES), sob o CAAE n: 52826016.2.0000.5542.

${ }^{2}$ Ver COMPROMISSO E ATITUDE. Legislação sobre violência contra as mulheres no mundo. Compromisso e atitude [online]. Disponível em: <http://www.compromissoeatitude.org.br/legislacao-sobre-violenciacontra-as-mulheres/>. Acesso em: 15 out. 2017.

3Breves exemplos foram as campanhas como "quem ama, não mata", palavras de (des) ordem como "a violência contra a mulher, não é o mundo que a gente quer" e o último movimento mundial da greve ou "parada" das mulheres, no 8 de março de 2017 que denunciava todo esse sistema patriarcal-racista-capitalista e o aviltamento à vida das mulheres com a regressão de direitos, conhecido como " 8 M". Em 2018, esse movimento internacionalista, principalmente latino-americano, se mantém vivo e declara "Pre-Para", informando que em 2018, todos os dias serão dias de luta das mulheres. O movimento é autônomo, sendo construído em cada território, considerando as particularidades regionais, porém articulado pela Internacional Feminista que se define como uma "Coalición de movimientos, redes, colectivos y organizaciones para impulsar campañas y fortalecer acciones de la lucha feminista en el mundo". Para maiores informações ver: <https://medium.com/@NosotrasParamos>.
} 


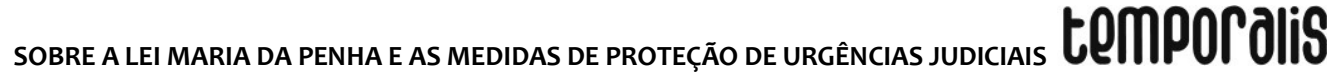

precedida por marcos legais internacionais ${ }^{4}$ e 3) a elaboração e divulgação das trágicas estatísticas de violências no cenário internacional e nacional5.

Nesse artigo realizamos reflexões sobre a violência contra as mulheres, articuladas com o debate acerca da proteção social e demonstrando algumas das contradições e violações de direitos presentes nessa procura por justiça e proteção, com vistas a fomentar um debate a ser cada dia mais travado em nosso horizonte ético-político, somados aos estudos já desenvolvidos sobre violências, na busca efetiva por uma mudança social substantiva, para além dos mecanismos burgueses já instituídos.

Para nós, pensar sobre a proteção social ofertada às mulheres que acionam o Estado pelo viés da judicialização, ao requisitarem medidas de proteção de urgência é tecer mediações com a própria configuração do Estado e funcionalidade de suas instituições. Como principais referências teóricas, estão as análises do feminismo materialista, da crítica marxista e lukácsianaao Direito, bem como pesquisadores/as da criminologia crítica e feminista.

Metodologicamente, selecionamos para a pesquisa de campo (2016-2017) ${ }^{6}$ a vara especializada em violência doméstica e familiar contra à mulher da capital brasileiraque mais mata as mulheres, Vitória, situada no estado do Espírito Santo (WAISELFISZ, 2015). À época da pesquisa, tal vara possuía 5994 processos, dentre esses 3154 de requisições de MPUs, ou seja, era sua principal demanda jurídica.

De acordo com nosso tempo, recursos e objetivos de pesquisa, o trabalho foi realizado com uma amostragem ${ }^{7}$ formada a partir da indicação de informantes-chave. Flick (2004) frisa a importância de termos bons/boas informantes que "[...] devem ter conhecimento e a experiência necessários sobre o assunto ou o objeto à sua disposição" (FLICK, 2004, p. 84). Os números de casos estudados dependiam da indicação e da memória dos/as informantes-chaves selecionados/as pela pesquisadora.

Foram informantes-chave para indicação dos processos, para fins de seleção da amostra, o/a juiz/juíza, um/a servidora do cartório e a equipe técnica (Serviço Social e Psicologia).

\footnotetext{
${ }^{4}$ Importante apontar o processo histórico de lutas, conferências e marcos legais internacionais, das quais o Brasil foi signatário, até a elaboração dessa legislação específica. Dentre eles, podemos destacar a Conferência Mundial sobre os Direitos Humanos de Viena em 1993, as Conferências Mundiais das Mulheres, sendo a quarta, realizada em Pequim, em 1995, resultando na "Declaração de Beijing", e as Convenções Sobre a Eliminação de Todas as Formas de Discriminação contra a Mulher, de 1979, e a Interamericana para Prevenir, Punir e Erradicar a Violência contra a Mulher, conhecida como "Convenção de Belém do Pará", de 1994.

${ }^{5}$ Temos por exemplo os Mapas e os Atlas da Violência, dentre outras pesquisas que levantam violências e violações sofridas pelas mulheres, como as pesquisas que vão abordar a feminização da pobreza, o encarceramento feminino, morte de mulheres em virtude do aborto inseguro, violências obstétricas e violações de outros direitos sexuais e reprodutivos, dentre outras.

${ }^{6}$ Buscamos compreender a lógica de atuação desse poder e a direção das medidas e não analisar condutas específicas de determinados sujeitos, por isso os processos são de distintas épocas e com atuações de diferentes profissionais. Tal cuidado também ocorreu devido questões éticas de sigilo e preservação da identidade de todos/as envolvidos/as. Todas as mulheres cujo processos foram estudados tiveram seus nomes substituídos pelos pseudonônimos de Marias.

7Segundo Flick (2004) tal amostra é estratégica para acessar " [...] casos típicos, caso críticos, casos delicados ou politicamente importantes ou até mesmo [utilizar] o critério da conveniência (casos mais fáceis de serem acessados)" (FLICK, 2004, p. 83).
} 
Desde já destacamos que, como utilizamos a memória dos/as informantes-chave nas sugestões, os únicos critérios de exclusão foram: 1) ações que já estivessem arquivadas definitivamente; 2) ações que com as indicações fornecidas pelos/as informantes não fossem passíveis de localização (por vezes lembrava-se do primeiro nome da pessoa que solicitou ou face a quem solicitou, por vezes apenas alguma característica dos sujeitos envolvidos ou ainda elementos quanto ao manuseio dos autos); 3) ações que em virtude da tramitação não estivessem fisicamente no cartório durante todo o processo da coleta de dados (recursos à $2^{\mathrm{a}}$ instância, cargas para advogado/a, Defensoria ou Ministério Público) 4) ações que não tivessem o processo de requisição de medidas de proteção, mas apenas inquéritos policiais ou ações penais (TENORIO, 2017).

Importante salientar que o Direito e o Judiciário, aparatos acionados por mulheres em situação de violência, possuem ritos e mecanismos que reproduzem outras violações, o que será demonstrado ao longo do artigo. Porém, apesar de estudarmos uma legislação, nosso foco não estará no debate de seus aspectos técnico-processuais, embora alguns sejam expostos, até mesmo porque há uma larga, permanente e necessária, discussão no âmbito do Direito ${ }^{8}$ que aborda teses jurisprudenciais, entendimentos e correntes doutrinárias, debate de competências, dentre outras questões específicas desse saber. Procuramos, em virtude disso, trazer elementos de outra área, da Política Social.

Selecionamos para esse artigo, algumas trajetórias de requisição de MPUs dos vinte processos estudados, para trazer algumas questões que podem ser analisadas, debatidas e aprofundadas. A função social desse artigo compromete-se com o movimento feminista, com as/os trabalhadores/as dos serviços que atendem essas mulheres, e, principalmente, volta-se para as próprias mulheres que resistem a um cotidiano de exploração, opressão e apropriação de seu tempo, de seu corpo, de suas escolhas e de suas vidas.

Para fins de exposição, realizamos inicialmente apontamentos sobre a Lei Maria da Penha, as opressões e a violência contra as mulheres e breves reflexões sobre o Estado e o Direito e suas ações de enfrentamento a essas violências. Posteriormente, trabalhamos com o debate acerca da proteção social dessas mulheres e algumas das contradições e violações de direitos presentes nessa procura por justiça e proteção nessa legislação. Por meio da história de nossas Marias, elencamos algumas questões que perpassam essas requisições judiciais de proteção: 1) acesso à justiça; 2) reprodução do machismo;3) punitivismo 4) falta de transversalidade das ações. Ao fim e ao cabo, trazemos considerações finais que giram em torno de que, mesmo após doze anos da LMP, ainda não temos sua implementação integral, e o que vem sendo aplicado, majoritariamente, é sua parcela mais limitada, menos transformadora da vida das mulheres.

\section{ANÁLISES SOBRE A LEI MARIA DA PENHA E MEDIDAS DE PROTEÇÃO DE URGÊNCIA SOB A PERSPECTIVA DA TOTALIDADE}

\footnotetext{
${ }^{8}$ Algumas das autoras são Campos (2011); Andrade (2012); Oliveira (2012); Souza (2013); Bianchini (2014); Fernandes (2015); Montenegro (2015), Boiteaux (2015), dentre muitas/os outras/os.
} 
Consideramos que para além da análise das opressões existentes na sociedade, cabe ainda avançarmos no debate crítico sobre as respostas que têm sido dadas a estas formas de opressão, sem descolá-las da análise da totalidade social, das condições de vida e de trabalho das mulheres. Santos (2009, p. 74) deixa nítido que pensar em uma perspectiva da totalidade não minimiza ou exclui a diversidade ou a individualidade, mas que a diversidade é uma expressão constituinte da individualidade mediadas pela sociabilidade:

O desafio está em reconhecer que a sociedade não é um somatório de indivíduos com suas experiências de vida e sentimentos singulares. Ao contrário, a vida social constitui-se numa totalidade articulada de complexos sociais parciais, nexos e relações que os indivíduos estabelecem entre si pela mediação de diferentes necessidades, sentimentos e interesses materiais (SOUZA, 2009, p.74).

Partimos do pressuposto que a sociedade está estruturada em processos de desigualdade de classe, raça e sexo, de forma imbricada, consubstancial e estes elementos não podem estar alheios de qualquer análise. Dessa forma, refletir sobre a violência contra a mulher é compreender tal fenômeno como resultante dessa estrutura balizada na exploração e nas opressões, não sendo um elemento restrito às relações individuais/conjugais, mas, resultado intrínseco dessa imbricação. Para fins de análise, nesse artigo, faremos alguns apontamentos sobre a categoria relações sociais de sexo, por considerar que ela nos subsidia na compreensão dessas relações antagônicas imersas na totalidade social (KERGOAT, 2010; DEVREUX, 2011; FALQUET, 2013; CISNE, 2014).

Devreux (2011) apontou que “[...] as relações sociais de sexo recobrem, então, todos os fenômenos de opressão, exploração e de subordinação das mulheres aos homens" (DEVREUX, 2011, p. 10). Portanto, as múltiplas dimensões dessas relações não se limitam ao espaço da família ou ao cenário doméstico. Problematiza tanto as explorações no âmbito do trabalho quanto o plano simbólico, o qual inferioriza e negativiza tudo que é vinculado ao feminino, tais esferas estão dialeticamente articuladas e em movimento histórico.

Para Almeida (2001), "[...] a violência expressa relações de forças que envolvem indivíduos inseridos desigualmente em relações sociais fundamentais de classe, gênero, étnicas, além das geracionais" (ALMEIDA, 2001, p. 6). É produto de relações sócio históricas, sendo manifestada por/em "[...] seres que corporificam relações sociais e não por indivíduos abstratos" (ALMEIDA, 2001, p. 2).

A violência contra à mulher assume, portanto, diferentes singularidades nessa totalidade, inclusive subjetivas, de acordo com as diferenças nacionais, regionais, sociais, econômicas e individuais. No Brasil, precisou-se adotar medidas jurídicas no enfrentamento à violência contra a mulher, após o país ser denunciado pelo Comitê Latino-Americano e do Caribe de Defesa dos Direitos da Mulher (CLADEM) e pelo Centro pela Justiça e Direito Internacional (CEJIL) à Comissão Interamericana de Direitos Humanos da Organização dos Estados Americanos (OEA) pelo caso de Maria da Penha Fernandes, mulher que sofreu várias violências físicas e tentativas de homicídio no casamento, e ficou paraplégica após levar um tiro disparado pelo marido?.

\footnotetext{
${ }^{9}$ Maria da Penha Fernandes, mulher brasileira cuja história de vida deu o nome à lei, durante 29 anos, sofreu sucessivas violências perpetradas pelo marido e pai de suas três filhas, o professor universitário e economista,
} 
A LMP é bem divulgada nacionalmente, apesar de seu conteúdo de forma mais detalhada ainda ser pouco conhecido pela maioria da população ${ }^{10}$. Constitui-se, não como o único, mas talvez o mais abordado atualmente, marco regulatório no enfrentamento à violência familiar e doméstica contra a mulher. Embora a questão da violência contra a mulher não seja nova, tal lei traz certa operacionalidade a essa demanda, com diretrizes de ação, o que não significa que sua operacionalização corresponde à forma como foi idealizada.

Porém, por compreendermos a violência de forma estrutural, como fenômeno social e não como um "problema" individual ou estritamente jurídico, a Lei Maria da Penha deve ser debatida na esfera da vida e das necessidades das mulheres em situação de violência, a serem atendidas pelos serviços sociais públicos e não apenas enquadrada em fórmulas jurídicas centralizadas em um sistema de justiça criminal movimentado por seus “especialistas", a quem Lukács (2013) engloba "[...] juízes e advogados até policiais e carrascos” (LUKÁCS, 2013, p. 247).

É possível notar, sem grande esforço, como o debate sobre proteção social, ainda está centrado nos aparatos coercitivos do Estado e nos mecanismos de repressão e de segurança pública. Ademais, sob uma perspectiva ontológica crítico dialética, o sistema jurídico de regulação situa-se como um "complexo" inserido na totalidade (complexo de complexos), um elemento histórico e ideológico da sociedade capitalista que possibilita avanços na direção da emancipação política (LUKÁCS, 2013; IASI, 2011).

Santos (2009) sinaliza que não podemos desvincular tal complexo parcial da dinâmica societária, já que os complexos parciais (direito, política, economia...) possuem certa autonomia, mas determinam e são determinados estruturalmente por múltiplas mediações.Há ainda um caráter fetichizado na abordagem da lei para o enfrentamento da relação desigual entre homens e mulheres, analisando a lei em si mesma, desconsiderando as interrelações entre a sociedade capitalista e a desigualdade entre homens e mulheres (TENORIO, 2017).

As legislações são importantes, mas permanecem sendo, nessa sociedade desigual, mecanismos que fazem parte da reprodução do status quo e, ao apresentar salvíficas soluções, não questionam os fundamentos dessa desigualdade. Marx ${ }^{11}$ ([1845-1846], 2007)

\footnotetext{
Marco Antônio Heredia Vivero. Em 1983, recebeu um tiro dele que resultou em sua paraplegia e, após retornar para casa, Vivero tentou eletrocutá-la e afogá-la durante o banho, o que a levou a denunciar a violência. Maria da Penha publicou, em 1994, o livro "Sobrevivi... posso contar" e Vivero publicou, em 2010, "A Verdade não contada no caso Maria da Penha" no qual nega ser autor das violências narradas. Vivero recebeu a primeira condenação em 1991, foi preso em 2002, 19 anos e 6 meses depois, e cumpriu dois anos da pena em regime fechado (OLIVEIRA, 2012).

${ }^{10}$ Recente pesquisa identificou que dentre as 1.116 mulheres entrevistadas, quando indagadas sobre a Lei Maria da Penha, afirmaram já ter ouvido falar sobre a lei, porém, $77 \%$ delas dizem conhecê-la pouco, enquanto apenas 18\% disseram que a conhecem muito (INSTITUTO DE PESQUISA DATA SENADO, 2017).

${ }^{11}$ Contemporaneamente, a tradição marxista ainda é acusada de economicista, insuficiente, mecanicista, reducionista, dogmática, omissa e, até mesmo romantizada (em relação à família proletária), para compreensão das questões da mulher ou “questões de gênero". Porém, pesquisadoras marxistas defendem que a contribuição do método, permitiu a desnaturalização da subordinação da mulher e nos ofereceu elementos para pensarmos as relações sociais historicamente construídas na sociedade capitalista (ARAÚJO, 2000; ANDRADE, 2011; SOUZA, 2014)
} 
adverte que, nesta ilusão, a lei aparece separada de sua base real. Não podemos esquecer, portanto, que "[...] a alienação no campo jurídico tem as mesmas raízes que o processo geral de estranhamento da forma de sociedade na qual determina o capital" (IASI, 2005, p. 189). Com tal embasamento teórico, construímos apontamentos sobre os limites no enfrentamento à violência contra à mulher pela Lei Maria da Penha.

Nas estatísticas de homicídios de mulheres, apesar de 31,2\% acontecerem na rua, a residência aparece com 27,1\%, "indicando a alta domesticidade dos homicídios de mulheres" (WAISELFISZ, 2015, p.39) demonstrando que a casa nem sempre é o local da proteção e do afeto, apesar da reflexão trazida em nossa epígrafe pelo poeta Galeano de que os direitos humanos deveriam começar em casa.

Segundo Waiselfisz (2015), a partir da vigência da Lei Maria da Penha, apenas cinco estados tiveram queda na taxa de violência, dentre eles o Espírito Santo, sendo os outros Rondônia, Pernambuco, São Paulo e Rio de Janeiro. O pesquisador destacou que os outros 22 estados tiveram grandes acréscimos em ritmos diferenciados como ocorreu com o primeiro colocado, Roraima, onde a violência aumentou 131,3\%.

Elencamos a seguir, a partir das histórias das Marias, para além dessas reflexões iniciais, algumas outras mediações necessárias para refletir sobre o acionamento e o enfrentamento à violência contra à mulher pela LMP. Importante salientar que esses elementos não estão em ordem de prioridade e nem estão separados na realidade, sendo vivenciados simultaneamente pelas mulheres que acessam a justiça, com menor ou maior intensidade, sendo assim analisados para fins de exposição:

\section{Dificuldade de acesso à justiça}

Ao analisarmos as solicitações de medidas de proteção de urgência encontramos diversas histórias, demandas e expectativas frente ao judiciário. Espaço este em que, na maioria das vezes, os papéis e suas verdades chegam antes das mulheres e que para acessá-lo, geralmente, necessita-se de um/a advogado/a ou defensor/a público/a.

Nesse subtópico, destacamos que todas as mulheres são passíveis de sofrerem violências nessa sociedade estruturalmente desigual, porém, considerando de forma não fragmentada, tanto sua subjetividade, quanto as condições materiais de sua existência, as trajetórias ou tentativas de rompimento com elas se dão de formas diferenciadas.

Não podemos desconsiderar que, quando o viés de apoio para essa superação da violência advém da judicialização, o recorte de classe nos salta aos olhos, para além da alusão à dependência econômica que já é amplamente debatida nas análises do rompimento da violência contra a mulher, trazemos outras mediações.

O acesso desigual à justiça é permeado por alguns elementos como: o sucateamento e precarização da Defensoria Pública (condição de ajuizamento de ação para a maioria das mulheres pobres); o não acesso ao conhecimento jurídico (falta de compreensão e de explicação sobre o conteúdo e o trâmite processual); a distância geográfica dos equipamentos (mulheres dos espaços periféricos da cidade, do campo, indígenas, ribeirinhas, quilombolas, migrantes...) e a fragmentação da competência híbrida (criminal e cível) das medidas judiciais. 
Destacamos que a previsão da competência híbrida dos Juizados de Violência Doméstica e Familiar não foi efetivada, e requisições vinculadas à separação, guarda, pensão alimentícia, visitação e divisão de bens, elementos muitas vezes decididos em outra vara, ainda vinculam essa mulher a um elo processual com a pessoa que a violentou. Conforme nos sinaliza Souza (2013):

[...] é a demanda cível uma das maiores preocupações das mulheres, tais como: separação de corpos, pensão alimentícia, indenização, partilha de bens, guarda. São impostos, contudo, inúmeros obstáculos para o atendimento destas demandas, como a própria falta de capacitação dos profissionais de Direito que militam nos JVDFCM (Juizados de Violência Doméstica e Familiar contra a Mulher), que têm formação penalista, e a exigência de uma demanda penal iniciada, como a ocorrência policial e/ou o oferecimento da denúncia pelo Ministério Público. Essa falta de atenção às demandas cíveis alimenta uma violência institucional, a banalização da violência e o desrespeito aos direitos desta mulher (SOUZA, 2013, não paginado).

Para as mulheres pobres que dependem do serviço público estatal de assistência judiciária gratuita, os agendamentos demorados, devido à sobrecarga da Defensoria Pública, agrava ainda mais esse quadro. Ainda, a falta de informações sobre o processo, bem como quanto a sequência dos ritos processuais, trazem às famílias uma série de desgastes, dentre eles, as idas e vindas nos espaços do sistema de justiça, que acarretam no custo da passagem do transporte público ou a demora do mesmo em regiões mais longínquas, ou ainda o risco de perda do trabalho por faltas, mesmo que justificadamente, ou o não ganho do preço diário da sua remuneração. Tais situações perpassaram os diversos casos analisados.

Maria Fernanda, por exemplo, enfrentou um longo processo na vara especializada e também se desenrolou paralelamente na vara de família, outra ação quanto a separação, guarda e visitação dos filhos. A Defensoria Pública, diante da ausência dela no comparecimento à vara, já sinalizava no curso do processo que ela poderia estar desacreditada do sistema de justiça, conforme trecho extraído dos autos pesquisados:

\begin{abstract}
A narrativa revela que a requerente recebeu orientação do Ministério Público no sentido de não adotar medidas que possam garantir a sua própria proteção acionar o botão do pânico no caso do requerido se aproximar dela dentro do bairro onde existem o que, se verdadeiros, representa posição com a qual este Defensor Público não concorda. Em todo caso, tais fatos podem ter levado a requerente por sua simplicidade e humildade a não mais confiar no sistema de Justiça [...] Parece, outrossim, que eventual análise do caso exige antes a contextualização da posição da ofendida no panorama de uma vítima de violência doméstica normalmente em estado de vulnerabilidade e desconhecimento dos trâmites processuais antes de ser preso por seu desinteresse na continuidade do feito. [...]. Ora, a distância da suposta vítima do poder público pode ser resultado da discordância e medo quanto à orientação - se é que existiu essa - do Ministério Público que pode ter afetado diretamente o comportamento dela fazendo a se sentir desprotegida e desiludida com a atuação do sistema de segurança a seu favor (TENORIO, 2017, p. 176).
\end{abstract}

O ex-marido foi preso várias vezes preventivamente, frequentou o "grupo reflexivo de gênero", mas as reclamações de descumprimento das MPUs persistiam. Segundo a equipe 
SOBRE A LEI MARIA dA PENHA E AS MEdidAs de PRoteÇÃo de URGÊNCIAS JUdiciaIS

técnica, a indicação do caso se deu porque "[...] as MPU e outras intervenções realizadas se mostraram insuficientes para resolver os conflitos existentes". Diante de tantas pressões sofridas pela justiça ("diversas audiências e necessidades constantes de comparecer à vara o que trazia prejuízos a sua vida laboral, suas alegações de descumprimento das medidas protetivas sendo questionadas"), fizeram com que ela, ao final, desistisse do processo.

\section{Reprodução do machismo institucional}

O requerimento das medidas de proteção pode ser feito pela mulher na Delegacia, pelo Ministério Público ou por defensor/a público/a ou advogado/a. As mulheres são atendidas pelo poder judiciário somente após provocação desses entes, ou seja, as mulheres dependem de mecanismos de acesso à justiça, conforme abordado no subtópico anterior. Importante salientar que esses espaços institucionais não estão livres do machismo e que essa porta de entrada pode trazer novas violências às mulheres que a procuram. Muitas vezes suas falas são desacreditadas e/ou o excesso de detalhes perguntado às mulheres naquele atendimento inicial pode trazer profundo sofrimento.

A primeira Delegacia Especializada no Atendimento à Mulher (DEAM) no Brasil, foi instaurada em 1985 em São Paulo. Atualmente, ao largo do território nacional existem DEAMs, onde as delegadas também são mulheres, porém, ainda são em número restrito e se encontram em ainda menor quantidade no interior. Destacamos que as delegacias especializadas não estão necessariamente nos municípios mais violentos para as mulheres. Também não funcionam fora do expediente regular e aos finais de semana, levando as mulheres à recorrerem, nessas ocasiões, às delegacias comuns.

Tal situação ocorreu com Maria Vitória, ao que foi relatado por seu advogado nos autos pesquisados, de que, os últimos acontecimentos, foram no final de semana e se sentira acuada na Delegacia de plantão. No documento encaminhado pela delegacia ao juízo relatando o caso, continha a seguinte análise do/a Delegado/a: "ressalto que as lesões existentes nos antebraços dela são arranhões, valendo esclarecer que ele possui unhas muito curtas, diferente dela cujas unhas são extremamente compridas", já sugerindo autolesionamento ${ }^{12}$.

Outros sofrimentos podem ser percebidos, por exemplo, no atendimento à Maria Flor, que sofrera violência sexual perpetrada pelo avô paterno desde os oito anos ${ }^{13}$. Procurou a delegacia somente aos 17 anos, após sofrer um aborto e ter ficado um período internada. Relatou que não havia contado a ninguém, pois “[...] como ele era uma pessoa próxima da família ninguém nunca imaginou [...]" e "[...] ele falava que já fez isso e não deu em nada e que ninguém acredita em criança [...]”, além de sofrer diversas ameaças à sua família.

\footnotetext{
${ }^{12} \mathrm{Em}$ nossa perspectiva de análise crítico-feminista não somos ingênuas em acreditar que não há mau uso da lei ou situações "forjadas por mulheres", até porque defendemos que mulheres são sujeitos capazes, numa ideia "radical de que mulher é gente" e que em sua humanidade podem optar por diferentes estratégias ou caminhos, porém, criticamos tais juízos já presentes nesse atendimento inicial recebido (TENORIO, 2017).

${ }^{13}$ Situações como a de Maria Flor remetem a necessidade de todos os espaços abrirem-se para ouvir crianças e adolescentes, considerando sua condição de sujeito em condição especial de desenvolvimento. Chama a atenção que não somente a fala delas poderia passar despercebida ou ser desacreditada, mas também de pessoa com transtorno mental, que tantas vezes é desqualificada nos processos.
}

Temporalis, Brasília (DF), ano 18, n. 36, p. 220-238, jul./dez. 2018. ISSN 2238-1856 
No termo de depoimento foi indagada se teve penetração, se usava camisinha, se já manteve relação sexual com outra pessoa, se acreditava que era filho/a do avô e se já havia contado para alguém. Tais interrogatórios fazem parte da construção do inquérito e da construção do crime, visando angariar elementos de "autoria e materialidade dos fatos".

Segundo Andrade (2012), o sistema penal duplica e não protege a vitimização da mulher, pois além da violência perpetrada pelo seu/sua agressor/a, enfrentará uma violência institucional em suas diversas facetas, pois se constitui um processo de controle que reproduz as desigualdades de classes e de gênero, ao que acrescentamos as desigualdades étnico-raciais, em suas palavras "[...] vivenciar toda uma cultura de discriminação, humilhação e estereotipia" (ANDRADE, 2012, p. 132). Segundo a pesquisadora, tal sistema não traz ruptura da opressão, se constituindo como um continuum de relações patriarcais, porém percebemos que, na contradição, este por vezes é o único mecanismo encontrado pelas mulheres e que, para algumas, se torna uma forma de romper com a violência que foi denunciada, ainda que de forma pontual.

A genitora de Maria Flor relatou a equipe técnica o sofrimento advindo da judicialização. Relatou que ela se distanciou, durante algum tempo, do acompanhamento do processo "[...] para poder continuar vivendo [...]", pois o fato de estar sempre monitorando o andamento dos autos a deixava muito abalada psiquicamente. Afirmou que, em consequência da situação, faz tratamento psicológico, pois tem tido dificuldade de falar em público e insônia.

O entendimento dos/as agentes e servidores/as que atendem essas mulheres pode fazer total diferença no encaminhamento da denúncia e no acolhimento e orientação das mulheres. Até porque, geralmente, a pessoa que é acusada de perpetrar violência não tem o perfil estereotipado daquela que comete crimes, de acordo com Fernandes (2015), "[...] em regra, os autores de violência doméstica não ostentam antecedentes em sua vida pregressa, muitos trabalham regularmente e exercem atividades lícitas" (FERNANDES, 2015, p. 182).

Outras possibilidades de desmerecimento do relato da mulher em situação de violência é o apelo ao seu suposto desequilíbrio psicológico e/ou emocional. Reforça-se a ideia da mulher histérica, descontrolada ou enganadora. O que compareceu no processo de Maria Betânia, quando o/a advogado/a particular do homem, desqualifica a decisão pelo fato das medidas terem sido impostas apenas pelo teor das declarações da pseudovítima.

\section{Punitivismo estatal}

O Direito Penal é pensado por diferentes vertentes da criminologia, das mais tradicionais/conservadoras às críticas e revolucionárias, que vão criticar o neoliberalismo e o aprofundamento do Estado Penal ou até mesmo apontar a necessidade de superação da criminalização dos comportamentos e buscar outras alternativas para a resolução dos conflitos e violências. 


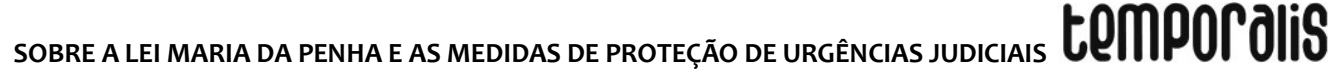

Andrade (2012) expõe sobre o profundo debate para a compreensão das relações entre criminalidade, sistema de justiça penal, criminalização e mulher/feminino. Para ela a criminologia é androcêntrica tanto no objeto do saber (mulher enquanto autora e vítima de crimes) quanto nos produtores do saber (sujeitos na produção da ciência).

Batista (2012) alega que o feminismo foi indiferente por muito tempo à criminologia crítica, porém seria a criminologia crítica também por muito tempo indiferente ao feminismo? Para Andrade (2012) é necessário um esforço integrador entre a Criminologia crítica e a Criminologia feminista.

Neste subtópico, a criminologia crítica e a criminologia feminista, nos auxiliam com suas lentes de análise. Quando abordamos o punitivismo estatal nessas ações de requisição de medidas de proteção, não estamos nos referindo à aplicação de penas nos processos criminais condenatórios, mas sim, a lógica punitivista que cerceia a operacionalização dessa legislação que foi relegada à justiça criminal, embora tenha apenas cinco artigos criminais. Dentre elas, a produção de provas, a deslegitimação da requisição quando a mulher não deseja representar criminalmente e a circunscrição a aplicação de medidas de restrição de direitos aos/às autores/as de violência e não de promoção deles às mulheres que a vivenciaram.

A Lei Maria da Penha prevê no art. $5^{\circ}$, incisos I, II e III, que a sua aplicação deve ser feita diante de qualquer ação ou omissão baseada no gênero nos casos em que há convívio permanente de pessoas, com ou sem vínculo familiar, na família, formada por indivíduos que são ou se consideram aparentados, unidos por laços naturais, por afinidade ou por vontade expressa ou, em qualquer relação íntima de afeto, atual ou anterior independentemente de coabitação ou de orientação sexual (BRASIL, 2006).

Em virtude dessas características, a violência doméstica e familiar é de difícil rompimento, também por se tratar de relações de afetividade em seus diversos arranjos e graus de vinculação. Portanto, muitas mulheres não desejavam ter estas pessoas punidas e/ou presas, só queriam não sofrer mais nenhuma violência, e serem protegidas, por saberem do sofrimento também trazido pelo sistema penal.

Maria Paula, por exemplo, conheceu a pessoa denunciada devido ao trabalho voluntário de aconselhamento religioso em unidades prisionais. As dificuldades e sofrimentos dele, que além de ter perdido completamente a visão, decorrente de violência sofrida no cárcere, a comoveu e passou a prestar-lhe auxílio, acompanhar em consultas e em seu tratamento. Ela solicitou medidas de proteção, inicialmente, por agressão física quando ele tentou estrangulá-la, sem representar criminalmente. Posteriormente desistiu das medidas de proteção em requisição feita pela Defensoria Pública, pois, para Maria Paula, seria um caso isolado, que ocorreu como resultado da violência estatal anterior que deixou sequelas na pessoa denunciada.

Já, outras mulheres consideravam a prisão como uma resposta à violência sofrida e diziam sentir-se mais seguras com tal determinação. Ainda havia aquelas que queriam uma responsabilização, mas que não fosse pelo viés da reclusão. Dos vinte casos estudados, nove desejaram representar criminalmente, sendo que dentre as nove, uma desistiu tanto das MPU, quanto da representação e retornou ao convívio com o marido, duas 
representaram-se mutuamente e tiveram seus casos posteriormente arquivados, e sete seguiram com a representação criminal.

Cabe destacar que alguns juízes e juízas ou operadores/as do direito, poderiam desqualificar o pedido das medidas de proteção quando as mulheres não desejavam representar criminalmente contra seus supostos agressores/as. Sabendo dessas tendências, advogados/as utilizavam tal questão como argumento para indeferimento ou deslegitimação do pedido. Foi o que baseou a petição do/a advogado/a do marido de Maria da Consolação para revogação das MPUs, um caso que envolvia, inclusive, violências físicas e já tinha medidas de proteção deferidas:

[...] não se verifica nos autos, gravidade na conduta do requerido que enseje uma medida cautelar tão danosa à família [...] Importante dizer que a revogação da $r$. decisão não impossibilita novo pedido da ofendida, caso volte a ser vítima de conduta agressiva do ofensor, podendo pleitear novas medidas protetivas de urgência a qualquer momento, podendo ainda pedir a instauração de inquérito policial e ajuizamento da ação penal cabível. Assim, dado o caráter excepcional das medidas protetivas, aliado ao desinteresse da vítima da representação, não há realmente como manter a r. decisão. Isto posto, requer-se à Eminente Magistrada, a revogação da medida cautelar, no afã de que possibilite ao requerente o retorno ao lar e ao seio familiar (TENORIO, 2017, p. 22).

De acordo com essa argumentação, caso houvesse nova violência, bastaria requerer novas medidas judiciais: uma retórica embasada na não representação criminal da mulher em situação de violência, que teve seu discurso deslegitimado e a necessidade de aplicação das medidas de proteção questionadas.

Oliveira (2012) aponta ainda os debates jurídicos em torno da constitucionalidade da lei, os quais trazem elementos para percebemos o discurso sobre a capacidade e autonomia da mulher. As decisões do Supremo Tribunal Federal (STF) ${ }^{14}$, em 2012, determinaram que, em casos de lesão corporal, ainda que leve, não se faz necessária a representação contra o/a autor/a da violência, o que chamamos de ação pública incondicionada, que é ajuizada pelo Ministério Público, independente da vontade da mulher. O Poder Judiciário, com seu saber legalista-formal, decide sobre quais as medidas necessárias para que a mulher esteja protegida. Para a autora, a lei possui avanços e também retrocessos em sua aplicação, pois, dentre outras questões, retira a autonomia feminina em alguns casos, de decidir pela continuidade ou não do processo penal.

As medidas de proteção de urgência constituíram-se uma importante inovação trazida pela lei e, a priori, são as que mais deveriam conter elementos articulados de contenção, assistência e prevenção da violência, já que proteção não se resume à punição e consideramos que nem perpassa por esta esfera.

Karam (2015) defende que ao invés de propormos ações negativas, que criminalizem condutas, proponhamos intervenções positivas, que promovam direitos fundamentais. Para tanto, deve-se garantir condições materiais, políticas e sociais para que esses se

\footnotetext{
${ }^{14}$ Vinculadas à Ação Direta de Constitucionalidade (ADC) no 19 e a Ação Direta de Inconstitucionalidade (ADI) $\mathrm{n}^{\circ} 4424$ no STF. Conferir Oliveira (2012).
} 


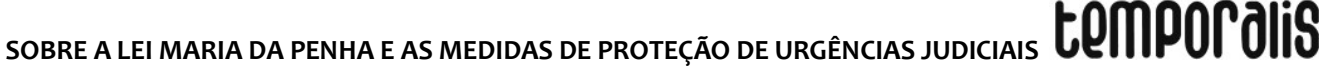

realizem. Pois se o enfoque for a punição, a mulher será esquecida, a estrutura sobre qual a violência se ergue será despercebida e a ilusão de que com a imposição da pena tudo estará resolvido é consolidada. Defendemos que ultrapassemos a aparência de avanço no acionamento da esfera penal, analisando se há outras possibilidades concretas de fortalecimento e proteção judicial das mulheres. Já indicamos que a legislação trouxe um relevante aparato institucional a ser implementado, além da desnaturalização e desprivatização da violência (TENORIO, 2017).

Dessa forma, refletir sobre a proteção das mulheres num espaço altamente punitivista e contraditório trouxe um caminho a ser trilhado nessa investigação. Percebemos que as mulheres não estão no centro do processo e nem são sujeitos neles. Falas conservadoras em defesa da família permeiam as argumentações em prol da não intervenção estatal. Ademais, muitas vezes alheias às alegações e aos trâmites processuais, essas mulheres desconhecem os mecanismos jurídicos e não são assistidas nesse percurso.

\section{Falta de transversalidade das ações}

O relato de retorno das mulheres ao judiciário, devido novas violências ou descumprimentos de MPUs, foi muito frequente nos casos estudados, por isso, e diante da dinamicidade da vida, o fortalecimento das mulheres precisa ser priorizado.

A lei prevê não somente a coibição da violência, mas também a implementação de políticas públicas de prevenção e assistência às mulheres em situação de violência doméstica e familiar, bem como aos demais membros da família, inclusive àquele/a que perpetrou a violência. Compreendemos que tal tripé, contenção, prevenção e assistência, precisa fazerse presente diante de tamanha complexidade e gravidade do fenômeno (CAMPOS, 2011; TENORIO, 2017).

Sabemos que o eixo da prevenção, por exemplo, seria mais difícil de ser alcançado por essa esfera, tendo em vista o seu caráter coletivo, porém os grupos reflexivos para pessoas autoras de violência ou campanhas educativas podem ser executadas em parceria com outras instituições do poder executivo, como o Centro de Referência Especializado da Assistência Social (CREAS) ou outros equipamentos vinculados à Política de Assistência Social e/ou à defesa dos Direitos Humanos (TENORIO, 2017).

A proteção social no sistema capitalista contemporâneo, nas palavras de Pereira (2013), é um processo complexo e contraditório, social, político e econômico. Couto (2015) salienta que essa proteção social se torna mais fragilizada com os ajustes estruturais necessários ao capital que se expressam em mercantilização e critérios excludentes de acesso às políticas sociais públicas. Aventamos que a LMP permanece centrada em um sistema de justiça criminal e não em um trabalho articulado de atendimento às mulheres em suas necessidades que não aparecem de imediato, mas que demandam acompanhamento e articulação entre os serviços. Sinalizamos, porém, que a inserção de equipes técnicas nos espaços judiciais podem fortalecer os atendimentos nessa direção.

A situação de pauperização e de outras expressões da questão social, comparecem nesses atendimentos, embora por vezes não estejam nos papéis iniciais do processo, e demonstram a necessidade de transversalização das ações da rede de serviços.Temos, por

Temporalis, Brasília (DF), ano 18, n. 36, p. 220-238, jul./dez. 2018. ISSN 2238-1856 
exemplo, a situação Maria Regina, 38 anos, negra, analfabeta. Expôs na delegacia que vivia maritalmente há 15 anos com o denunciado e que possuíam dois filhos juntos. Declarou que estavam separados de corpos há um ano e três meses. A equipe técnica relatou nos autos que já acompanhava o caso de longa data, sendo essa a segunda vez que ela solicitou medidas de proteção:

\begin{abstract}
Em função das constantes situações de violência vivenciadas, Sra. [Maria Regina] solicitou medidas protetivas de urgência. Na ocasião, houve a prisão preventiva do requerido, a aplicação das medidas de proibição de contato e aproximação, e afastamento do lar. Apesar de tais medidas, ao sair da prisão, [ele] retornou para casa. Sra. [Maria Regina], diante de uma situação de extrema dependência socioeconômica - sem documentação civil, analfabeta, desempregada e sem nenhum rendimento próprio - e acreditando numa possível mudança de comportamento do requerido, permitiu o seu regresso (TENORIO, 2017, p. 73).
\end{abstract}

Percebemos que os retornos desse homem ao lar foram motivados também por uma situação de pobreza, baixa escolarização, desemprego, ou seja, pela dificuldade de Maria Regina suprir as necessidades materiais de si e dos filhos, aliados a um sentimento idealizado de transformação dele. Tal caso necessitou de amplas articulações com a rede de proteção social e demonstrou que o atendimento à violência não se circunscreve somente as relações familiares, mas também a ausência ou ineficácia de outras ações do Estado.

A situação de Maria Regina demonstrou também o papel desenvolvido pela equipe multidisciplinar, direcionado à proteção social, com articulações voltadas para sua assistência, para além da situação de violência vivenciada:

Esta equipe acompanhou a requerente no sentido de orientá-la e viabilizar o acesso à documentação civil, encaminhamentos para a Defensoria Pública com a finalidade de abertura de ação com pedido de alimentos, e encaminhamento para os serviços de assistência social do município de Vitória para inclusão em programa de renda mínima e acesso a benefícios eventuais (TENORIO, 2017, p. 227).

Após retornar para acompanhamento, a equipe relatou que "[...] naquela ocasião, [ela] apresentou-se com maior nível de autonomia. Havia conseguido sua documentação civil e a pensão alimentícia dos filhos estava regularizada”. Um ano após, a requerente compareceu a esta equipe, em função da aplicação de novas medidas protetivas de urgência. Após tal situação, Maria Regina mudou-se de endereço.

Foi realizada pela equipe visita institucional à Unidade Básica de Saúde e visita domiciliar. Já estava separada, porém desempregada e residia em imóvel alugado. Os filhos estudavam em tempo integral na escola e, segundo seus relatos, o ex-marido descumpria as medidas protetivas constantemente.

A rede de atendimento é fundamental no acolhimento e acompanhamento da demanda, constituindo-se por diferentes serviços e políticas públicas que atendem, identificam e encaminham as situações de violência, dividindo-se em serviços especializados e não especializados (BRASIL, 2011). Reforçamos assim, que os serviços públicos e privados que possuem usuárias mulheres, precisam estar atentos a essa demanda das violências em suas 


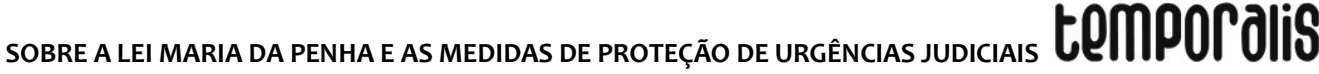

diversas manifestações (física, sexual, patrimonial, psicológica ou moral) para realizarem o acolhimento e as orientações necessárias, sabendo que a escolha dos caminhos a serem adotados devem ser da própria mulher e que precisa ser respeitada enquanto sujeito de sua própria história e por vezes demandarão um longo tempo de caminhada.

\section{CONSIDERAÇÕES FINAIS}

Maria da Penha Fernandes, apoiada por instituições de defesa, ao levar para âmbito internacional seu depoimento, representou as denúncias já publicizadas pelo movimento feminista desde a segunda metade do século XX, sobre a opressão vivenciada pelas mulheres, como uma questão política e não privada ou particular. Portanto, de forma simbólica, representou tantas "Marias" que não teriam recursos concretos de publicar um livro ou acionar as organizações feministas ou esferas jurídicas e institucionais, nacional ou internacionalmente.

Negar tal percurso e restringir seu ganho a uma possibilidade retributiva da violência, qual seja, punir os agressores, é limitar a potencialidade de falar sobre a violência historicamente sofrida por mulheres e de acionamento das políticas públicas brasileiras que devem se comprometer com o atendimento dessas que, provavelmente, tiveram em suas trajetórias muitas violações, simplesmente por serem mulheres.

As mulheres sempre tiveram suas vidas atravessadas e impactadas por legislações ou instituições coercitivas, sendo também essas uma de suas arenas de luta e resistências, na busca por direitos e ampliação dos aparatos legais de acordo com suas pautas. Os elementos apresentados demonstram que os limites de rompimento da violência não são meramente subjetivos, não dependem exclusiva ou individualmente da mulher que denuncia ou que não denuncia.

Consideramos que a proteção social das mulheres precisa ser mais debatida, tendo em vista que os ganhos advindos de marcos legais, não necessariamente resultam em ações concretas de acordo com as demandas reais da população. Entendemos que a Lei 11.340/2006, é sancionada em um contexto neoliberal de recuo nos investimentos estatais nas políticas sociais públicas, o que a torna de difícil implementação, principalmente no que se refere a sua rede de atendimento, especializada ou não especializada na violência contra a mulher.

Visualizamos que o próprio sistema de justiça não atende os requisitos sugeridos pelo CNJ em termos estruturais. Ademais, as instituições seguem a mesma lógica da sociedade em que são gestadas, tendo seus mecanismos de funcionamento também arraigados em estruturas de hierarquização com expressões elitistas, machistas e racistas em sua operacionalização.

A centralização do enfrentamento à violência contra a mulher na segurança pública e no aparato policialesco é um outro elemento que nos traz contradições e limitações. A fomentação da delegacia como porta de entrada para medidas de proteção denota que ela seria a outra face da repressão/punição estatal que sabemos a quem se dirige, a quem seleciona. 
Compreendemos que as outras alternativas de solicitação de MPUs, como via Defensoria Pública/Advocacia Privada ou Ministério Público, precisam ser fortalecidas/oferecidas como opção às mulheres que não se sentem à vontade de acionar esse mecanismo ou não desejam representar criminalmente contra o/a autor/a de violência e, portanto, não ensejam a instauração de um inquérito policial.

Sendo assim, embora a lei traga inovações, o eixo coercitivo ainda predomina no poder judiciário em virtude, inclusive, de sua própria condição de existência. Percebemos que a proteção social ofertada à mulher são as mais superficiais e imediatistas, que não demandam investimentos em políticas públicas. Voltam-se para a restrição de direitos dos homens (principais denunciados), medidas que sempre estão acompanhadas do fantasma da prisão preventiva,pouco promovendo inserção em políticas públicas de prevenção ou acompanhamento para os/as envolvidos/as, trazendo um reducionismo ao próprio espírito da lei e conservando o tradicional papel do direito.

Além disso, a Lei Maria da Penha tem sofrido ataques sob a forma fetichizada de conquistas, como ocorreu, por exemplo a alteração dos nomes dos Juizados e Varas especializadas em violência doméstica e familiar contra a mulher, por Justiça pela Paz em Casa, inspirada em uma campanha do Conselho Nacional de Justiça homônima.

Em nossa perspectiva teórico-política, a violência é expressão das opressões estruturais desta sociedade, das relações sociais de classe, raça e sexo, e não apenas um fenômeno cultural. Decerto, reafirmamos os limites de qualquer alternativa dentro desta sociedade que não contemple superá-la ao construir outra forma de sociabilidade. As alterações legais não são nosso horizonte ético-político na busca pela emancipação humana de mulheres e homens, e sim, conquistas civilizatórias que nos permitem minimamente reafirmar e denunciar as desigualdades e violências existentes e acionar a responsabilidade estatal pela vida das mulheres, cientes de suas limitações e riscos.

\section{REFERÊNCIAS}

ALMEIDA, Suely Souza de. Violência e subjetividades. In: SEMINÁRIO LATINO AMERICANO DE ESCUELAS DE TRABAJO SOCIAL, 17., Lima, 2001. Anais..., Lima, Peru, 2001.

ANDRADE, Joana El-Jaick. O Marxismo e a questão feminina: articulações entre gênero e classe no âmbito do feminismo revolucionário. Tese (Doutorado em Sociologia)Universidade de São Paulo, São Paulo, 2011.

ANDRADE, Vera Regina Pereira de. Pelas mãos da criminologia: o controle penal para além da (des)ilusão. Florianopólis: Instituto Carioca de Criminologia, 2012. (Coleção Pensamento Criminológico).

ARAÚJO, Clara. Marxismo, feminismo e o enfoque de gênero. In: FERREIRA, Muniz et al. Crítica Marxista, São Paulo: Boitempo, n. 11, p. 65-70, 2000. 


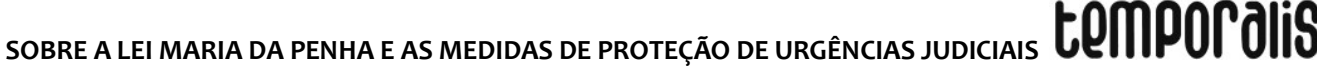

BATISTA, Vera Malaguti. Introdução crítica à criminologia brasileira. Rio de Janeiro: Revan, 2011.

BRASIL. Presidência da República. Lei $\mathrm{n}^{\circ}$ 11.340, de 7 de agosto de 2006, cria mecanismos para coibir a violência doméstica e familiar contra a mulher, nos termos do $\S 8^{\circ}$ do art. 226 da Constituição Federal, da Convenção sobre a Eliminação de Todas as Formas de Discriminação contra as Mulheres e da Convenção Interamericana para Prevenir, Punir e Erradicar a Violência contra a Mulher; dispõe sobre a criação dos Juizados de Violência Doméstica e Familiar contra a Mulher; altera o Código de Processo Penal, o Código Penal e a Lei de Execução Penal; e dá outras providências. Brasília (DF), 2006.

BRASIL. Secretaria Nacional de Enfrentamento à Violência contra as Mulheres. Secretaria de Políticas para as Mulheres. Rede de Enfrentamento à Violência contra as Mulheres. Brasília (DF), 2011.

BRASIL. Presidência da República. Lei n 13.505, de 08 de novembro de 2017. Acrescenta dispositivos à Lei no 11.340, de 7 de agosto de 2006 (Lei Maria da Penha), para dispor sobre o direito da mulher em situação de violência doméstica e familiar de ter atendimento policial e pericial especializado, ininterrupto e prestado, preferencialmente, por servidores do sexo feminino. Brasília (DF), 2017.

BIANCHINI, Alice. Lei Maria da Penha: aspectos assistenciais, protetivos e criminais da violência de gênero. São Paulo: Saraiva, 2014.

BOITEAUX, Luciana et al. Mulheres e crianças encarceradas: um estudo jurídico-social sobre a experiência da maternidade no sistema prisional do Rio de Janeiro. Rio de Janeiro: Grupo de Pesquisa em Política de Drogas e Direitos Humanos do Laboratório de Direitos Humanos da Universidade Federal do Rio de Janeiro, 2015.

CAMPOS, Carmen Hein (Org.). Lei Maria da Penha Comentada em uma Perspectiva Jurídico-Feminista. Rio de Janeiro: Lumen Juris, 2011. p. 173-183

CISNE, Mirla. Relações sociais de sexo, raça/etnia e classe: uma análise feministamaterialista. Temporalis, Brasília (DF), n. 28, p. 133-149, jul./dez. 2014.

COMPROMISSO E ATITUDE. Legislação sobre violência contra as mulheres no mundo. Compromisso e atitude [online]. Disponível em: <http://www.compromissoeatitude.org.br/legislacao-sobre-violencia-contra-as-mulheresno-mundo/>. Acesso em: 15 out. 2017.

COUTO, Berenice Rojas. Debate: Proteção Social em tempos de capitalismo financeiro. Argumentum, Vitória, v. 7, n. 2, p. 22-23, jul./dez, 2015.

DEVREUX, Anne-Marie. A teoria das relações sociais de sexo: um quadro de análise sobre a dominação masculina. Cadernos de Crítica Feminista, Recife: SOS Corpo, ano 5, n. 4, p. 6- 29, dez. 2011. 
FALQUET, Jules. O capitalismo financeiro não liberta as mulheres: análises feministas materialistas e imbricacionistas. Crítica Marxista, Campinas: IFCH/UNICAMP, n. 36, 2013.

FERREIRA, Verônica et al (Orgs.). O Patriarcado desvendado: teorias de três feministas materialistas: Collete Guillaumin, Paola Tabet e Nicole Claude Mathieu. Recife: SOS Corpo, 2014 .

FERNANDES, Valéria Diez Scarance. Lei Maria da Penha: o processo Penal no caminho da efetividade. São Paulo: Atlas, 2015.

FLICK, Uwe. Plano de pesquisa. In: FLICK, Uwe. Uma introdução à Pesquisa Qualitativa. 2. ed. Porto Alegre: Bookman, 2004. p. 69-88.

IASI, Mauro Luís. Direito e Emancipação humana. Revista da Faculdade de Direito, São Paulo: Universidade Metodista de São Paulo, v. 2, p.170-192, 2005.

INSTITUTO DE PESQUISA DATASENADO. Violência doméstica e familiar contra a mulher: pesquisa DataSenado. Brasília (DF): Senado Federal, jun. 2017. Disponível em: <http://agenciapatriciagalvao.org.br/wpcontent/uploads/2017/06/DataSenado_RelatorioVDFCM2017_vfinal.pdf >. Acesso em: 12 jun. 2017.

INSTITUTO DE PESQUISA ECONÔMICA APLICADA (IPEA); FÓRUM BRASILEIRO DE SEGURANÇA PÚBLICA (FBSP). Atlas da Violência 2016. Brasília, DF, 2016. Disponível em: < https://www12.senado.leg.br/institucional/omv/entenda-a-violencia/pdfs/atlas-daviolencia-2016>. Acesso em: 22 jul. 2016.

INSTITUTO DE PESQUISA ECONÔMICA APLICADA (IPEA); FÓRUM BRASILEIRO DE SEGURANÇA PÚBLICA (FBSP). Atlas da Violência 2017. Rio de Janeiro, jun. 2017. Disponível em: <http://www.ipea.gov.br/portal/images/170609_atlas_da_violencia_2017.pdf>. Acesso em: 01 nov. 2017.

KARAM, Maria Lúcia. Os paradoxais desejos punitivos de ativistas e movimentos feministas. Justificando [online], artigos, 13 mar. 2015. Disponível em: <http://justificando.com/2015/03/13/os-paradoxais-desejos-punitivos-de-ativistas-emovimentos-feministas/>. Acesso em: 14 abr. 2016.

KERGOAT, Danièle. Dinâmica e consubstancialidade das relações sociais. Novos estudos, CEBRAP, São Paulo, n. 86, p. 93-103, mar. 2010. Disponível em: <http://www.scielo.br/pdf/nec/n86/n86a05.pdf>. Acesso em: 14 mar. 2016.

LUKÁCS, Gyorgy. Para uma ontologia do ser social II. São Paulo: Boitempo, 2013. MONTENEGRO, Marília. Lei Maria da Penha: uma análise criminológico-crítica. Rio de Janeiro: Revan, 2015. 


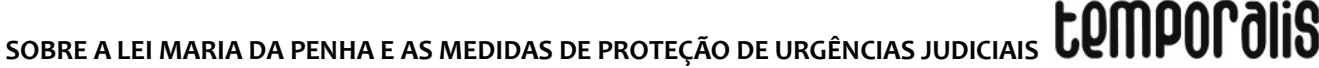

OLIVEIRA, Magali Gláucia Fávaro de. Usurpação estatal da autonomia da mulher e/ou efetivação do direito fundamental à igualdade de gêneros?: Um estudo bourdieusiano das modificações feitas à lei maria da penha pela ação direta de inconstitucionalidade $\mathrm{n}^{\circ}$ 4424. Dissertação (Mestrado em Direito) - Faculdade de Direito de Vitória, Vitória, 2012.

PEREIRA, Camila Potyara. Proteção social no capitalismo: contribuições à crítica de matrizes teóricas e ideológicas conflitantes. Tese (Doutorado em Serviço Social)Universidade de Brasília, Brasília, DF, 2013.

SANTOS, Silvana Mara de Morais dos. Direitos, desigualdade e diversidade. In: BOSCHETTI, Ivanete et al (Orgs.). Política social no capitalismo: tendências contemporâneas, 2. ed. São Paulo: Cortez, 2009. p. 64-86.

SOUZA, Luanna Tomaz de. Lei Maria da Penha e demanda punitiva. Compromisso e atitude [online], seção artigos, direito, 21 jun. 2013. Disponível em:

<http://www.compromissoeatitude.org.br/wpcontent/uploads/2013/06/LUANNATOMAZ_LMPeademandapunitivaREVISADO21072013.p df>. Acesso em: 01 nov. 2017.

SOUZA, Vanessa Bezerra de. Gênero, Marxismo e Serviço Social. Temporalis, Brasília (DF): Associação Brasileira de Ensino e Pesquisa em Serviço Social, ano 14, n. 27, p. 13-31, jan./jul. 2014.

TENORIO, Emilly Marques. Entre a polícia e as políticas: análise crítico-feminista da lei maria da penha e das medidas de proteção de urgência judiciais. Dissertação (Mestrado em Política Social)-Universidade Federal do Espírito Santo, Vitória, 2017.

WAISELFISZ, Julio Jacobo. Mapa da Violência 2015: Homicídios de Mulheres no Brasil. Brasília, DF: OPAS/OMS, ONU Mulheres, SPM e Flacso, 2015. Disponível em:

<http://www.mapadaviolencia.org.br/mapa2015_mulheres.php>. Acesso em: 20 nov. 2015. 